\title{
Follow-Up Study On Physical And Neurodevelopmental Outcomes In Extremely Preterm Infants At The Corrected Age Of 12 Months
}

\author{
Jing Wang \\ Nanjing Medical University \\ Yang Yang \\ Children's hospital of Nanjing Medical University \\ Xin Zhang \\ Nanjing Maternity and Child Health Care Hospital \\ Yue Jiang \\ Nanjing Maternity and Child Health Care Hospital \\ Xiaojie Guo \\ Nanjing Medical University \\ Qu Xu \\ Nanjing Maternity and Child Health Care Hospital \\ Lei Yang \\ Nanjing Maternity and Child Health Care Hospital \\ Min Zhang \\ Nanjing Maternity and Child Health Care Hospital \\ Qin Hong \\ Nanjing Maternity and Child Health Care Hospital \\ Xia Chi \\ Nanjing Medical University \\ Meiling Tong ( $\sim$ tml_2014@126.com) \\ Nanjing Maternity and Child Health Care Hospital
}

\section{Research Article}

Keywords: DQ, extremely preterm, physical development

Posted Date: February 16th, 2022

DOI: https://doi.org/10.21203/rs.3.rs-1290560/v1

License: (c) (1) This work is licensed under a Creative Commons Attribution 4.0 International License. Read Full License 


\section{Abstract}

Objective: This study aimed to investigate the physical and neurological outcomes of extremely preterm infants (EPIs) at the corrected ageof 12 months, to provide the basis for parents and doctors to make treatment decisions.

Methods: The follow-up data of EPIs who survived and were discharged from Women's Hospital of Nanjing Medical Universityduring 2018-2020 were analyzed. The weight, length, and head circumference by age were recorded and compared with those ofterm infantsto investigate the catch-up growth of EPIs. Children at 12 months' corrected agewere assessed using the Gesell Developmental Scale.The relationship of basic data with the catch-up growth and nervous system development was also discussed.

Results: In totaL, 70 infants were included in this study. At the 1-year visit, the EPIs were larger than the 50th percentile for weight, length, and head circumference $(\mathrm{HC})$ of the World Health Organization Child Growth Standards. The percentages of catch-up in weight, length, and HC were all greater than $50 \%$.Our multivariate logistic regression showed that the higher the weight gain in the first year of life $(\mathrm{OR}=1.45,95 \% \mathrm{Cl}: 1.04-2.03, P=0.03)$, the higher the body length gain $(\mathrm{OR}=5.72,95 \% \mathrm{Cl}: 1.08-30.21, P=0.04)$, the higher the birth weight $(\mathrm{OR}=1.03,95 \% \mathrm{Cl}: 1.01-1.02, P=0.01)$, and the higher the weight gain $(\mathrm{OR}=1.32,95 \% \mathrm{Cl}: 1.09-1.61, P=0.01)$, which would induce the catch-up growth of EPIs. Furthermore, after 1 year of follow-up, the proportions of mild-tomoderate abnormal development quotient (DQ) in the five functional domains were all greater than $10 \%$. Hence, theearly catch-up growth was beneficial for neurodevelopment.

Conclusions: Close developmental surveillance is of great significance in improving the long-term quality of life of EPIS.

\section{Introduction}

Prematurity was defined according to the World Health Organization(WHO) report, which classifies extremely preterm infants (EPIs) as individuals born before 28 weeks of gestational age. The medical treatment and diagnosis capacity for EPIs significantly improved, and the survival rate of EPIs substantially increased owing to the rise and development of perinatal medicine, as well as the markedly improved technical levels in neonatal intensive care units (NICUs) ${ }^{[1,2]}$.According to the WHO, it is estimated that China has the second-highest number of premature births in the world ${ }^{[3]}$. EPIs account for about $4.1 \%$ of all preterm births. However, it must be considered that EPIs are a different group in terms of their anatomical and physiological maturity, where the risk of adverse outcomes is the highest ${ }^{[4,5]}$. Therefore, it is important to emphasize the care of EPIs around prognosis rather than the survival rate.

Understanding the effects of the neurodevelopmentof EPIsfor both families and services that provide care are necessary. Developmental follow-up for EPIs should be an integral part of their clinical care. A detailed neurodevelopmental assessment gives families specific information for supporting their child's development through anticipatory guidance, as well as a pathway to early intervention following the identification of any delay or disability. At a service level, understanding the effect of EPIs on developmental outcomes is needed to evaluate and inform ongoing clinical practice and to counsel families.

Although efforts have been made in China to improve the survival rate of EPIs, few comprehensive clinical analyses on EPIs have been conducted, and largesample clinical data to analyze the growth of EPIs and the main neurodevelopment-related factors are lacking. The present study aimed to assess the physical and neurological prognoses of EPIs, providing the basis for parents and doctors to make treatment decisions.

\section{Methods}

The study was approved by the Institutional Review Board of Nanjing Maternity and Child Health Care Hospital. Written informed consent was obtained from all the patients' families before their participation.

The primary study sample consisted of EPIs treated atthe NICU inWomen's Hospital of Nanjing Medical University between January 2018 and October 2020 ( $n$ $=160)$. The exclusion criteria for the study included severe congenital malformation $(n=11)$; death before the age of 1 year ( $n=29)$; infants with incomplete medical records $(n=25)$; infants with suspected genetic, metabolic, or chronic disease $(n=12)$; and those with growth and developmental follow-ups at some other hospital $(n=13)$. The final study sample consisted of 70 preterm infants. Children were stratified according to the gestational age at birth (GA): $24-25+6$ weeks, 26-26+6 weeks, and 27-27+6 weeks; and birth weight: <1000 g (VLBW) and 1000-1500 g (ELBW).

The information regarding the perinatal and neonatal period was obtained by a systematic examination of the participants' medical records, including personal health booklets, hospital discharge notes, and follow-up or outpatient information notes.

\section{Physical measurement}

The physical traits recorded were $\mathrm{HC}$, body length, and body weight, which were measured three times during the first year after birth. Adequate catch-up growth was defined as a body weight reaching the 25th percentile of the corrected age for the appropriate-for-gestational-age children ${ }^{[6]}$.

\section{Neurological developmental assessment}

Neurobehavioral development for infants at the corrected age of 12 months was assessed using the Gesell Developmental Scale (GDS), which contained five subscales of gross motor, fine motor, adaptive behavior, language, and social behavior. Infant development was assessed using the development quotient (DQ) according to the following criteria: normal $\left(\mathrm{DQ}^{3} 85\right)$, borderline $(75 £ \mathrm{DQ}<85)$, and abnormal $(\mathrm{DQ}<75)$.

\section{Statistical analysis}


Data were double entered, verified for accuracy, and analyzed using SPSS 21.0. All results were expressed as mean values \pm standard deviation. Differences in population rates between the two or more groups were evaluated using the chi-squared test. Data were evaluated using analysis of variance or $t$ test for comparisons between groups. The logistic regression analysis was used to determine the factors for catch-up growth. $P<0.05$ indicated a statistically significant difference.

\section{Results}

\section{Physical growth}

The study involved 70 VLBW/ELBW EPIs, including 30VLBW with a mean gestational age of (25.13 \pm 0.77$)$ weeks and a mean birth weight of (838.17 \pm 91.35$)$ $\mathrm{g}$, and 40ELBW with a mean gestational age of $(26.63 \pm 0.58)$ weeks and a mean birth weight of $(1143.01 \pm 108.84) \mathrm{g}$; the differences between the two groups were statistically significant $(P<0.05)$. The singleton and twin birth cases in VLBWand ELBW groupswere 21 and 9 , and 35 and 5 , respectively, but no statistically significant differenceswere foundbetween the two groups ( $P>0.05)$. The natural labor in the VLBWand ELBW groups was 25 and28, respectively; statistically significant differences were found between the two groups $(P<0.05)$ (Table 1$)$.

Table 1 A completion of the clinical data in the two groups

\begin{tabular}{|c|c|c|c|c|}
\hline & $\operatorname{VLBW}(\mathrm{n}=30$ case $)$ & $\operatorname{ELBW}(\mathrm{n}=40$ case $)$ & $\mathrm{t} / \mathrm{c} 2$ & $\mathrm{p}$ \\
\hline GA(weeks) & $25.13 \pm 0.77$ & $26.63 \pm 0.58$ & -9.17 & $\varangle 0.01$ \\
\hline \multirow[t]{2}{*}{ Sex } & male(16) & male(25) & \multirow[t]{2}{*}{0.59} & \multirow[t]{2}{*}{0.44} \\
\hline & female(14) & female(15) & & \\
\hline \multirow[t]{2}{*}{ multiple birth } & singleton $₫ 21 \rrbracket$ & singleton $\varangle 35 \square$ & \multirow[t]{2}{*}{3.28} & \multirow[t]{2}{*}{0.07} \\
\hline & twins $₫ 9 \rrbracket$ & twins $₫ 5 \rrbracket$ & & \\
\hline \multirow[t]{2}{*}{ Fertilization way } & natural conception $\varangle 20 \rrbracket$ & natural conception $₫ 24 \rrbracket$ & \multirow[t]{2}{*}{0.33} & \multirow[t]{2}{*}{0.56} \\
\hline & assisted reproductive technology(ART) $ه 10 \rrbracket$ & ARTQ16ه & & \\
\hline \multirow[t]{2}{*}{ Delivery modes } & natural labor $₫ 25 \rrbracket$ & natural labor $₫ 28 \rrbracket$ & \multirow[t]{2}{*}{0.06} & \multirow[t]{2}{*}{0.005} \\
\hline & cesarean section $₫ 5 \rrbracket$ & cesarean section $₫ 12 \rrbracket$ & & \\
\hline Birth weight $₫ g \unrhd$ & $838.17 \pm 91.35$ & $1143.01 \pm 108.84$ & -9.87 & $\otimes 0.01$ \\
\hline Birth body length(cm) & $32.33 \pm 2.68$ & $35.63 \pm 2.70$ & -5.06 & $\varangle 0.01$ \\
\hline Birth head circumference(cm) & $23.52 \pm 1.37$ & $25.86 \pm 1.12$ & -6.24 & $\varangle 0.01$ \\
\hline \multirow[t]{3}{*}{ Apgar's score } & Apgar's score $\leq 3(4)$ & Apgar's score $\leq 3(5)$ & \multirow[t]{3}{*}{9.93} & \multirow[t]{3}{*}{0.007} \\
\hline & $4 \sim 7(18)$ & $4 \sim 7(10)$ & & \\
\hline & $\geq 8(8)$ & $\geq 8(25)$ & & \\
\hline \multirow[t]{2}{*}{ Mother's height before pregnancy $(\mathrm{cm})$} & $\triangle 160 \mathrm{~cm} \otimes 3 \rrbracket$ & $\otimes 160 \mathrm{~cm} \otimes 10 \bigotimes$ & & \\
\hline & $\geq 160 \mathrm{~cm} \otimes 27 \rrbracket$ & $\geq 160 \mathrm{~cm} \otimes 30 \otimes$ & 1.29 & 0.255 \\
\hline growth rate of weight ${ }^{\mathrm{a}}(\mathrm{g} /$ day $)$ & $30.76 \pm 5.97$ & $30.16 \pm 7.93$ & 0.34 & 0.72 \\
\hline growth rate of body length ${ }^{\mathrm{b}}(\mathrm{cm} /$ month $)$ & $2.96 \pm 0.92$ & $3.10 \pm 0.62$ & -0.79 & 0.43 \\
\hline growth rate of head circumference ${ }^{\mathrm{c}}(\mathrm{cm} / \mathrm{month})$ & $1.21 \pm 0.27$ & $1.44 \pm 0.38$ & -2.78 & 0.007 \\
\hline
\end{tabular}

${ }^{a}$ growth rate of weight: the weight gain rate from 1 to 3 months of life $\square^{\mathbf{b}}$ growth rate of body length $\varangle$ the body length gain rate from 1 to 3 months of life $\square^{\mathbf{c}}$ growth rate of $\mathrm{HC} \otimes$ the $\mathrm{HC}$ gain rate from 1 to 3 months of life.

At the 1-year visit, the EPIs included in this study were larger than the 50th percentile for weight, length, and HC of the WHO Child Growth Standards. At the corrected age of 3 and 6 months, rapid growth was most pronounced. It showed a steady upward trend and then decreased slightly over the remaining months, especially in terms of body length and HC (Table 2).

Table 2 Physical growth (mean \pm SD) at different ages by infant sex 


\begin{tabular}{|c|c|c|c|c|c|}
\hline & \multirow[t]{2}{*}{ corrected GA } & male & \multirow[t]{2}{*}{ percentile } & female & \multirow[t]{2}{*}{ percentile } \\
\hline & & Mean $\pm S D$ & & Mean $\pm S D$ & \\
\hline \multirow{3}{*}{$\begin{array}{l}\text { Weight } \\
(\mathrm{kg})\end{array}$} & 3 & $6.67 \pm 1.13$ & $\mathrm{P}_{50} \mathbb{\otimes} \mathrm{P}_{75}$ & $6.63 \pm 0.71$ & $\mathrm{P}_{75} \bowtie \mathrm{P}_{80}$ \\
\hline & 6 & $8.33 \pm 1.59$ & $\mathrm{P}_{50} \llbracket \mathrm{P}_{75}$ & $8.20 \pm 0.85$ & $P_{75} \bowtie P_{80}$ \\
\hline & 12 & $9.65 \pm 1.72$ & $P_{50} \otimes P_{75}$ & $8.91 \pm 1.64$ & $P_{50} \otimes P_{75}$ \\
\hline \multirow[t]{3}{*}{ body length (cm) } & 3 & $61.22 \pm 2.87$ & $\mathrm{P}_{25} \llbracket \mathrm{P}_{50}$ & $61.68 \pm 2.80$ & $\mathrm{P}_{75} \llbracket \mathrm{P}_{80}$ \\
\hline & 6 & $68.12 \pm 3.04$ & $\mathrm{P}_{50} \otimes \mathrm{P}_{75}$ & $68.66 \pm 2.85$ & $P_{80} \otimes P_{95}$ \\
\hline & 12 & $74.82 \pm 3.10$ & $\mathrm{P}_{25} \llbracket \mathrm{P}_{50}$ & $74.39 \pm 3.66$ & $\mathrm{P}_{50} \otimes \mathrm{P}_{75}$ \\
\hline \multirow[t]{3}{*}{ head circumference $(\mathrm{cm})$} & 3 & $40.47 \pm 1.22$ & $\mathrm{P}_{25} \llbracket \mathrm{P}_{50}$ & $40.00 \pm 1.09$ & $P_{50} \llbracket P_{75}$ \\
\hline & 6 & $43.44 \pm 1.30$ & $\mathrm{P}_{50} \otimes \mathrm{P}_{75}$ & $42.62 \pm 1.10$ & $P_{50} \otimes P_{75}$ \\
\hline & 12 & $45.44 \pm 1.28$ & $\mathrm{P}_{25} \llbracket \mathrm{P}_{50}$ & $44.49 \pm 1.94$ & $P_{25} \llbracket P_{50}$ \\
\hline
\end{tabular}

As shown in Table 3, the percentage of catch-up in weight in the VLBW groupwas $28 \%, 26 \%$,and $32 \%$, the percentage of catch-upin weight in the ELBW groupwas $33 \%, 31 \%$, and $31 \%$; however, no statistically significant differenceswere foundbetween the two groups ( $P>0.05)$. The percentage of catch-up in body length in the VLBW groupwas $25 \%, 23 \%$, and $25 \%$, and the percentage of catch-up in body length in the ELBW groupwas $33 \%, 28 \%$,and $29 \%$, but no statistically significant differenceswere observedbetween the two groups ( $P>0.05$ ). The percentage of catch-up in HCin the VLBW groupwas $30 \%, 26 \%$, and $27 \%$,and the percentage of catch-up in $\mathrm{HCin}$ the ELBW groupwas $32 \%, 27 \%$, and $29 \%$,the differences between the two groups were statistically significant at corrected 12 months $(P<0.05)$ (Table 3).

Table 3 Completion of catch-up growth

\begin{tabular}{|c|c|c|c|c|c|c|c|}
\hline & & \multicolumn{6}{|c|}{ corrected age (month) } \\
\hline & & 3 & & 6 & & 12 & \\
\hline \multirow[t]{2}{*}{ weight } & VLBW & $28 \%$ & total $(61 \%)$ & $26 \%$ & total(57\%) & $32 \%$ & total $(63 \%)$ \\
\hline & ELBW & $33 \%$ & & $31 \%$ & & $31 \%$ & \\
\hline \multirow[t]{2}{*}{ body length } & VLBW & $25 \%$ & total(58\%) & $23 \%$ & total(51\%) & $25 \%$ & total $(54 \%)$ \\
\hline & ELBW & $33 \%$ & & $28 \%$ & & $29 \%$ & \\
\hline \multirow[t]{2}{*}{ head circumference } & VLBW & $30 \%$ & total(62\%) & $26 \%$ & total(53\%) & $25 \%^{*}$ & total $(56 \%)$ \\
\hline & ELBW & $32 \%$ & & $27 \%$ & & $31 \%^{*}$ & \\
\hline
\end{tabular}

$\star \rrbracket c 2=0.39 \rrbracket p \otimes 0.05$.

The logistics regression analysis was performed assuming whether suitable catch-up growth could be achieved as the dependent variable. It was conducted with sex, multiple birth, GA, birth weight, birth body length, birth HC, mother's height before pregnancy,Apgar's score,growth rate of weight,growth rate of body length, and growth rate of $\mathrm{HC}$ as independent variables. The assigned values of the multivariate regression variables are shown in Table 4.

Our multivariate logistic regression analysis showed that the higher weight gain rate from 1 to 3 months of life $(\mathrm{OR}=1.45,95 \% \mathrm{Cl}: 1.04-2.03, P=0.03)$ would induce catch-up growth of EPIs of weight, the higher body length gain rate from 1 to 3 monthsof life $(\mathrm{OR}=5.72,95 \% \mathrm{Cl}: 1.08-30.21, P=0.04)$ would induce catch-up growth of EPIs of body length, and the higher birth weightrate(OR $=1.03,95 \% \mathrm{Cl}: 1.01-1.02, P=0.01)$ and the higher weight gain rate from 1 to 3months of life (OR $=1.32,95 \% \mathrm{Cl}: 1.09-1.61, P=0.01)$ would induce catch-up growth of EPIs of HC(Table 5).

Table 4 Assigned values of the multivariate regression variables 


\begin{tabular}{|c|c|}
\hline Factors & assigned values \\
\hline sex & $1=$ male $₫ 2=$ female \\
\hline multiple birth & $1=$ singleton $₫ 2=$ twin \\
\hline GA & numerical variable \\
\hline Birth weight & numerical variable \\
\hline Birth body length & numerical variable \\
\hline Birth head circumference & numerical variable \\
\hline Mother's height before pregnancy & $1=\rrbracket 160 \mathrm{~cm}, 2=\geq 160 \mathrm{~cm}$ \\
\hline Apgar's score & $1=$ Apgar's score $\leq 3 \rrbracket 2=4 \sim 7 \rrbracket 3=\geq 8$ \\
\hline Fertilization way & $1=$ Natural conception $₫ 2=$ ART \\
\hline Delivery modes & $1=$ Natural labor $\otimes 2=$ Cesarean section \\
\hline growth rate of weight & numerical variable \\
\hline growth rate of body length & numerical variable \\
\hline growth rate of head circumference & numerical variable \\
\hline
\end{tabular}

Table 5 A multivariate logistic analysis of the catch-up growth of the EPIS

\begin{tabular}{|c|c|c|c|c|c|c|}
\hline & Factors & B & SE & Wald c2 & $\mathrm{P}$ & $\mathrm{OR}(95 \% \mathrm{Cl})$ \\
\hline weight & growth rate of weight & 0.37 & 0.17 & 4.82 & 0.03 & $1.45 \rrbracket 1.04 \rrbracket 2.03 \rrbracket$ \\
\hline body length & growth rate of body length & 1.74 & 0.85 & 4.22 & 0.04 & $5.72 \varangle 1.08 \rrbracket 30.21 \rrbracket$ \\
\hline \multirow[t]{2}{*}{ head circumference } & birth weight & 0.01 & 0.01 & 7.04 & 0.01 & $1.03 \rrbracket 1.01 \rrbracket 1.02 \rrbracket$ \\
\hline & growth rate of weight & 0.28 & 0.10 & 8.03 & 0.01 & $1.32 \rrbracket 1.09 \rrbracket 1.61 \rrbracket$ \\
\hline
\end{tabular}

\section{Neurological development}

Using GDS, the proportion of mild-to-moderate abnormal DQ of adaptability, gross motor movement, fine movement, language, and personal social contact at the corrected age of 12 months was $17.1 \%, 12.9 \%, 15.7 \%, 20.9 \%$, and $14.3 \%$, respectively. Further, $10.2 \%$ were scored $>85$ in all the five functional areas (Table 6). The factors that influenced DQ were also investigated.

The effect of catch-up growth on DQ was studied for infants who had recently completed their bodily catch-up growth.The results indicated that the CG group of weight had significantly higher DQ scores compared with the NO-CG group ingross motor movement domains. Also, theCG group of body length had significantly higher DQ scores than the NO-CG group inadaptability and fine movement domains. However,the CG group of HCshowed no significant difference compared with the NO-CG group in anyof thedomains (Table 7).

Table 6 Results of GDS at the corrected age of 12 months

\begin{tabular}{|llll|}
\hline Functional domains & Normal & Borderline & Abnormal \\
\hline Adaptability & $41.4 \%$ & $41.5 \%$ & $17.1 \%$ \\
\hline Gross motor movement & $48.6 \%$ & $38.5 \%$ & $12.9 \%$ \\
\hline Fine movement & $40.0 \%$ & $44.3 \%$ & $15.7 \%$ \\
\hline Language & $31.4 \%$ & $47.7 \%$ & $20.9 \%$ \\
\hline Personal social contact & $45.7 \%$ & $40.0 \%$ & $14.3 \%$ \\
\hline
\end{tabular}

Table 7 A comparison of DQ of the EPIs of the catch-upgrowth in the two groups 


\begin{tabular}{|c|c|c|c|c|c|c|c|c|c|c|c|c|c|}
\hline & & \multicolumn{3}{|l|}{ Adaptability } & \multicolumn{3}{|c|}{ Gross motor movement } & \multicolumn{3}{|c|}{ Fine movement } & \multicolumn{3}{|l|}{ Language } \\
\hline & & mean $\pm S D$ & $\mathrm{t}$ & $\mathrm{p}$ & mean $\pm S D$ & $t$ & $\mathrm{p}$ & mean $\pm S D$ & $t$ & $\mathrm{p}$ & mean $\pm S D$ & $\mathrm{t}$ & $\mathrm{p}$ \\
\hline \multirow[t]{2}{*}{ weight } & CG & $82.21 \pm 7.63$ & \multirow[t]{2}{*}{-0.45} & \multirow[t]{2}{*}{0.65} & $88.86 \pm 4.10$ & \multirow{2}{*}{-3.15} & \multirow[t]{2}{*}{0.008} & $83.62 \pm 8.32$ & \multirow[t]{2}{*}{-0.55} & \multirow[t]{2}{*}{0.58} & $80.25 \pm 9.40$ & \multirow{2}{*}{-0.23} & \multirow[t]{2}{*}{0.81} \\
\hline & $\begin{array}{l}\text { NO- } \\
\text { CG }\end{array}$ & $82.90 \pm 8.50$ & & & $82.90 \pm 8.50$ & & & $85.43 \pm 7.45$ & & & $81.14 \pm 9.70$ & & \\
\hline \multirow[t]{2}{*}{ body length } & $\mathrm{CG}$ & $83.09 \pm 9.10$ & \multirow[t]{2}{*}{2.06} & \multirow[t]{2}{*}{0.04} & $83.54 \pm 8.51$ & \multirow[t]{2}{*}{0.09} & \multirow[t]{2}{*}{0.92} & $85.06 \pm 8.54$ & \multirow[t]{2}{*}{3.13} & \multirow[t]{2}{*}{0.003} & $80.15 \pm 10.29$ & \multirow[t]{2}{*}{-0.31} & \multirow[t]{2}{*}{0.75} \\
\hline & $\begin{array}{l}\text { NO- } \\
\text { CG }\end{array}$ & $79.81 \pm 4.61$ & & & $83.38 \pm 5.25$ & & & $79.56 \pm 5.25$ & & & $81.00 \pm 6.15$ & & \\
\hline \multirow{2}{*}{$\begin{array}{l}\text { head } \\
\text { circumference }\end{array}$} & CG & $82.34 \pm 7.60$ & \multirow[t]{2}{*}{-0.008} & \multirow[t]{2}{*}{0.99} & $82.73 \pm 8.64$ & \multirow[t]{2}{*}{-1.55} & \multirow[t]{2}{*}{0.07} & $8334 \pm 7.96$ & \multirow[t]{2}{*}{-0.93} & \multirow[t]{2}{*}{0.35} & $79.54 \pm 9.36$ & \multirow[t]{2}{*}{-1.44} & \multirow[t]{2}{*}{0.16} \\
\hline & $\begin{array}{l}\text { NO- } \\
\text { CG }\end{array}$ & $82.36 \pm 7.66$ & & & $86.57 \pm 6.43$ & & & $85.64 \pm 9.22$ & & & $83.57 \pm 9.46$ & & \\
\hline
\end{tabular}

\section{Discussion}

Currently, the birth rate of EPIs in China has increased, and the treatment success rate is significantly higher than earlier. Gestational age and weight make EPIs even more susceptible to the effects of perinatal growth retardation, unlike normal full-term infants. The perinatal growth retardation is followed by a period of catch-up growth, which usually starts in early infancy ${ }^{[7]}$.Some previous studies suggested that achieving catch-up growth in an early stage after birth was a significant factor in long-term growth and neurodevelopment outcomes ${ }^{[8,9]}$. A relatively high percentage of preterm infants achieved catch-up growth during the first year of life ${ }^{[10]}$. Although less research on the catch-up of EPIs has been conducted in China, the data from our study indicated that the weight, length, and $\mathrm{HC}$ all rose rapidly within the corrected age of 6 months, but the growth rate slowed down after the corrected age of 6 months. In addition, the total rates of catch-up in weight, body length, and $\mathrm{HC}$ all reached more than $50 \%$ at the corrected age of 3,6 , and 12 months, respectively. It was possible that EPIs benefited from the improvements in nutritional support and routine follow-up and then experienced a period of accelerated postnatal growth before the corrected age of 6 months. The peak catch-up growth rates for weight, length, and HC were noted before 6 months, which had important clinical implications.It should be noted, in terms of growth levels and catch-up growth rates, a slight downward trend was observed from 6 months,especially for HC in the VLBE group.Some of the children in this age group included those transiting from breast milk to complementary foods, which, when given, might not be adequate in terms of both nutrient content and amount of intake to meet the requirements for growth. However, to support this hypothesis, additional studies focusing not only on dietary patterns but also on other aspects of feeding habits are needed to better understand the role of early feeding habits.

Our study showed that birth weight, weight, and body length gain rates from 1 to 3 months of life were the protective factors for EPIs.Birth weight played an important role in the prognostication of growth and development of preterm infants with systemic structural and functional maturation; it is one of the main determinants of future physical and brain development.Our study suggested that the effects of early infancy weight and body length gain seemed to be conducive to catch-up growth. Hack et al., however, discussed that catch-up growth throughout infancy was associated with the measures of obesity at the age of 14 and was therefore not beneficial ${ }^{[11]}$. A study on infants with gestational age less than 32 weeks and/or birth weight less than $1500 \mathrm{~g}$ and followed up over 10 years found that higher weight or height at the age of 5 years was associated with greater weight at the age of 1 year ${ }^{[10]}$.

The GDS is used to evaluate the function of the central nervous system, which consists of five domains, including the adaptive domain, gross motor domain, fine motor domain, language domain, and social domain. Preterm infants show an increased risk of adverse consequences in various aspects of the development of premature babies, especially in terms of cognitive function and language. Our study findings were consistent with previous results ${ }^{[12,13]}$. LBW infants are at a higher risk of growth restriction and delayed motor and language development in the later stage ${ }^{[14,15]}$. Early catch-up growth is beneficial for neurodevelopment ${ }^{[16]}$. Our findings showed that the CG group of weight and body length had a higher DQ of neurological outcomes than the NO-CG group.It has been suggested that a smaller $\mathrm{HC}$ is related to poorer cognitive outcomes ${ }^{[17]}$, but our study investigating neurodevelopment did not find an association between catch-up growth for $\mathrm{HC}$ and neurocognitive outcomes.Studies have shown almost one third of EPIs with some degree of developmental delay or abnormality until the age of 2 years ${ }^{[18]}$. This study suggested that the catch-up growth in the first year could be closely monitored to early identify impaired cognition in the high-risk preterm infants.

In conclusion, our study cohort consisted solely of EPIs, a population rarely studied previously. The EPI survival rate continues to improve with the development of neonatal medicine. The present study suggested that physical growth and neurological development remained a significant problem for prematurely born infants in the first year. Besides physical growth retardation and inability to catch up with their peers in height, weight, and HC, some EPIs are at increased risk of early developmental delays, especially in speech-language development. Further studies should aim at high-risk groups of EPIs to adopt the principle of "early detection, early intervention" to help and support in preventing or reducing the occurrence of developmental delays.

\section{Declarations}

\section{Data availability}

All datasets generated for this study are included in the manuscript and/or the supplementary files.

\section{Ethics approval and consent to participate}


The study was approved by the Institutional Review Board of Nanjing Maternity and Child Health Care Hospital. All participants provided written informed consent. All methods performed in accordance with relevant regulations and guidelines.

\section{Consent for publication}

Not applicable

\section{Availability of data and materials}

Not applicable

\section{Competing interests}

The authors declare no competing interests.

\section{Fundings}

This work was supported in part by The Subproject of Key Research and Development Program of China (2016YFC1000204-6), Jiangsu Provincial Medical Innovation Team (CXTDA2017001), The "six talent peak" High-level Talents Training Project of Jiangsu Province (WSN-165), Key Project Supported by Medical Science and Technology Development Foundation Nanjing Department of Health (zkx18044), Specialized disease cohort study of Nanjing Medical University (NMUC2018014A), Nanjing Medical Science and Technique Development Foundation (YKK19115)

\section{Author contributions}

Tong $\mathrm{M}$ and Chi X designed the study. Wang J, Yang Y, Zhang X and Guo X carried out the study and collected data. Wang J, Zhang M and Hong Q conducted the statistical analysis and interpretation. Wang $\mathrm{J}$ wrote the report. Tong $\mathrm{M}$ and $\mathrm{Chi} \mathrm{X}$ revised the report. All the authors reviewed the report and approved the final version.

\section{Acknowledgments}

We would like to thank all the children and mothers for their cooperation in data collection. Clinical staff in Nanjing Maternity and Child Health Care Hospita were extremely helpful during implementation and included Dr.Tong M ,Dr. Chi X, Dr. Hong Q , and we thank all the others for providing implementation support and conducting data collection.

\section{References}

[1] Choi S H, Park Y S, Shim K S, et al. Recent trends in the incidence of multiple births and its consequences on perinatal problems in Korea[J]. J Korean Med Sci, 2010,25(8):1191-1196.

[2] Wu X P, Gu C L, Han S P, et al. A multicenter retrospective study on survival rate and complications of very preterm infants[J]. Zhongguo Dang Dai Er Ke Za Zhi, 2021,23(8):814-820.

[3] Chawanpaiboon S, Vogel J P, Moller A B, et al. Global, regional, and national estimates of levels of preterm birth in 2014: a systematic review and modelling analysis[J]. Lancet Glob Health, 2019,7(1):e37-e46.

[4] Blencowe H, Cousens S, Chou D, et al. Born too soon: the global epidemiology of 15 million preterm births[J]. Reprod Health, 2013,10 Suppl 1:S2.

[5] Schlapbach L J, Adams M, Proietti E, et al. Outcome at two years of age in a Swiss national cohort of extremely preterm infants born between 2000 and 2008[J]. BMC Pediatrics, 2012,12(1).

[6] Danhua W, Xihong L. Recommendations for feeding preterm or low birth weight infants after hospital discharge[J]. Zhonghua Er Ke Za Zhi, 2016,54(01):612.

[7] Euser A M, de Wit C C, Finken M J, et al. Growth of preterm born children[J]. Horm Res, 2008,70(6):319-328.

[8] Knops N B, Sneeuw K C, Brand R, et al. Catch-up growth up to ten years of age in children born very preterm or with very low birth weight[J]. BMC Pediatr, 2005,5:26

[9] Westerberg A C, Henriksen C, Ellingvag A, et al. First year growth among very low birth weight infants[J]. Acta Paediatr, 2010,99(4):556-562.

[10] Deng Y, Yang F, Mu D. First-year growth of 834 preterm infants in a Chinese population: a single-center study[J]. BMC Pediatrics, 2019,19(1).

[11] Hack M, Schluchter M, Margevicius S, et al. Trajectory and correlates of growth of extremely-low-birth-weight adolescents[J]. Pediatr Res, 2014,75(2):358366 .

[12] Adams-Chapman I, Watterberg K L, Nolen T L, et al. Neurodevelopmental outcome of preterm infants enrolled in myo-inositol randomized controlled trial[J]. Journal of Perinatology, 2021,41(8):2072-2087. 
[13] Barnes-Davis M E, Williamson B J, Merhar S L, et al. Extremely preterm children exhibit altered cortical thickness in language areas[J]. Scientific Reports, $2020,10(1)$.

[14] Streimish I G, Ehrenkranz R A, Allred E N, et al. Birth weight- and fetal weight-growth restriction: impact on neurodevelopment[J]. Early Hum Dev, 2012,88(9):765-771.

[15] Wang B, Sun J, Sun Y, et al. A clinical analysis of very and extremely low birth weight preterm infants[J]. Am J Transl Res, 2021,13(8):9395-9403.

[16] Belfort M B, Gillman M W, Buka S L, et al. Preterm infant linear growth and adiposity gain: trade-offs for later weight status and intelligence quotient[J]. J Pediatr, 2013,163(6):1564-1569.

[17] Yu W H, Wang S T, Chen L W, et al. Effect of first-month head-size growth trajectory on cognitive outcomes in preterm infants[J]. J Formos Med Assoc, 2022,121(1 Pt 2):367-374.

[18] Taczała J, Latalski M, Dmoszyńska-Graniczka M, et al. Neurodevelopmental outcome and early rehabilitation of premature babies - is it needed in the first 2 years of life?[J]. Annals of Agricultural and Environmental Medicine, 2021,28(1):172-178. 